\title{
Materialidades do trabalho digital no Sul global e invisibilidades comunicacionais
}

\author{
Rafael Grohmann
}

Doutor em Ciências da Comunicação pela Universidade de São Paulo (USP). Professor do Programa de Pós-Graduação em Comunicação da Faculdade Cásper Líbero.

E-mail: rafael-ng@uol.com.br

Resumo: $O$ livro $O$ privilégio da servidão: o novo proletariado de serviços na era digital, de Ricardo Antunes, oferece uma leitura sobre as mutações e contradições do mundo do trabalho, passando pelas materialidades do trabalho digital e pelas morfologias da "classe-que-vive-do-trabalho", em um diálogo tanto teórico-conceitual a partir do Sul global quanto em uma análise conjuntural dos últimos anos no Brasil, incluindo a contrarrevolução burguesa e a devastação do trabalho no governo Temer. Procuramos, então, trazer um diálogo da obra com a comunicação.

Palavras-chave: trabalho digital; mundo do trabalho; Sul Global; classes sociais; comunicação.
Abstract: The book The Privilege of Servitude: The New Services-Proletariat in the Digital Age, by Ricardo Antunes, offers a reading of the mutations and contradictions of the world of work, through the materialities of digital labour and the morphologies of the "class-thatlives-from-labour", in a dialogue both theoretical-conceptual from the Global South and in a conjunctural analysis of the last years in Brazil, including the bourgeois counterrevolution and the devastation of the labour in the Temer government. The review aims to make Antunes' book dialogue with communication research.

Keywords: digital labour; world of work; Global South; social classes; communication. 
1. MURDOCK, Graham. Refeudalização revisitada: a destruição da democracia deliberativa. MATRIZes, São Paulo, v. 12, n. 2, p. 1331, 2018.

2. ANTUNES, Ricardo. O privilégio da servidão: o novo proletariado de serviços na era digital. São Paulo: Boitempo, 2018.

3. Ibidem, p. 16.

4. Ibidem, p. 16

5. FISHER, Mark. Capitalist Realism: is there no alternative? Winchester: Zero Books, 2011.

6. DARDOT, Pierre; LAVAL, Christian. A nova razão do mundo. São Paulo: Boitempo, 2016.

7. BROWN, Wendy. El pueblo sin atributos: la secreta revolución del neoliberalismo. Barcelona: Malpaso, 2016

8. ANTUNES, op. cit., p. 287.

9. HUWS, Ursula. Labor in the global digital economy. New York: Monthly Review Press, 2014.

10. SINGER, André. O lulismo em crise: um quebra-cabeça do período Dilma (2011-2016). São Paulo: Companhia das Letras, 2018.

11. CARVALHO, Laura. Valsa brasileira: do boom ao caos econômico. São Paulo: Todavia, 2018.

12. ANTUNES, op. cit., p. 262.

13. PRADO JÚNIOR, Caio. Formação do Brasil contemporâneo. São Paulo: Companhia das Letras, 2011.

14. FERNANDES, Florestan. A Revolução Burguesa no Brasil. São Paulo: Globo, 2006

15. Ibidem

16. Este, ao menos, nos discursos da campanha eleitoral.

17. ANTUNES, op. cit.

18. Idem. Os sentidos do trabalho. São Paulo: Boitempo, 2001.
Em tempos de ascensão institucional da extrema direita no Brasil, destruição do pacto construído em 1988 e de um projeto de país autônomo, democrático e progressista - inclusive com a destruição da democracia deliberativa, como aponta Murdock ${ }^{1}$-, o livro mais recente de Ricardo Antunes, O privilégio da servidão: o novo proletariado de serviços na era digital ${ }^{2}$, não é somente um alento, mas um diagnóstico potente - realista sem se furtar de enxergar uma "luz no fim do túnel" - em relação ao Brasil contemporâneo, do ponto de vista do mundo do trabalho. Sua potência se deve principalmente à centralidade, na análise, da vida concreta e material dos sujeitos trabalhadores, e à dialética, levando em consideração o processo histórico, sempre contraditório. Antunes abre o livro ${ }^{3}$ falando que atualmente parece que vivemos em uma "era das trevas", mas há pouco tempo atrás, perto de 2013, a conjuntura era marcada por uma chamada "era das rebeliões". O autor, então, se pergunta: "quem poderá dizer, então, que o sistema de metabolismo social do capital, com sua era das contrarrevoluções, é o fim da história?"4.

Se não é, pois, o fim da história, é preciso: (1) desnaturalizar e enfrentar o "realismo capitalista", no sentido de não o tomar como único modo de produção e modo de vida possível, em um momento no qual a "governamentalidade neoliberal" ${ }^{6}$ penetra em todas as esferas da vida ${ }^{7}$, significando, portanto, uma confrontação com a lógica destrutiva do capital $^{8}$; (2) pensar em (e propor) formas de resistência, considerando que não há controle sem resistência, como afirma Huws ${ }^{9}$ em relação ao mundo do trabalho atual.

Nesse contexto, $O$ privilégio da servidão se une a outras obras recentes, como as de André Singer ${ }^{10}$ e de Laura Carvalho ${ }^{11}$, no sentido de compreender a conjuntura nacional e sua crise. Contudo seu foco não é nem o lulismo nem as matrizes econômicas da última década, mas as lutas de classes e a nova morfologia da classe trabalhadora, com uma dominação burguesa oscilante entre "conciliação pelo alto" e "golpe"12. Caio Prado Júnior ${ }^{13}$ já enunciava a "superexploração da força de trabalho" e a transformação "pelo alto" no capitalismo periférico brasileiro. Mas é principalmente em Florestan Fernandes ${ }^{14}$ que Antunes se baseia para falar em uma contrarrevolução burguesa no cenário contemporâneo. Neste contexto, podemos recuperar Fernandes ${ }^{15}$, para quem a burguesia brasileira não é moderna ou paladina da civilização, fazendo tudo o que for para ela vantajoso, inclusive tirar proveito das persistentes desigualdades. Em um artifício de conciliação pela unificação das classes possuidoras, não há ruptura definitiva com o passado. O que há é um processo lento, molecular e encapuzado, nesse caso, de devastação e desconstrução do trabalho com Temer-Bolsonaro ${ }^{16}$.

O livro de Antunes ${ }^{17}$ é, pois, a consolidação de um processo de pesquisa desenvolvido desde Os sentidos do trabalho ${ }^{18}$, como um livro de maturidade que apresenta tanto as categorias para compreensão da atualidade do trabalho frente às tecnologias digitais quanto a análise da precarização e da flexibilização do trabalho no Brasil, deixando claro que a precarização não é algo estático, 
mas "um modo de ser intrínseco ao capitalismo"19. O autor mostra, portanto, um olhar do Sul global para o mundo do trabalho sem deixar de dialogar com autores do Norte, clássicos e contemporâneos. Antunes apresenta, então, a consolidação do argumento de que o "fim da sociedade do trabalho" era um delírio europeu-habermasiano ${ }^{20}$, mostrando tanto as novas morfologias do mundo do trabalho - como o proletariado de serviços, a pejotização, o infoproletariado e o trabalho digital - quanto a persistência do trabalho precário global. Não se fala de "fim do trabalho" na China, na Índia ou no Brasil (e mesmo os europeus têm enfrentado essa questão de forma mais concreta na última década).

A precarização do trabalho, como algo inserido no modo de produção capitalista, faz com que contratos de trabalho antes tidos como "atípicos" - freelancers, pessoas jurídicas (PJs), contratos de zero hora, trabalhos intermitentes, terceirização - se tornem a regra da contrarrevolução burguesa no Brasil, em linha com aquilo já diagnosticado por outros autores no Norte global, como Boltanski e Chiapello ${ }^{21}$ e Dardot e Laval $^{22}$. O imperativo da flexibilidade é a base da reorganização produtiva por parte da gestão empresarial, envolvendo a individualização das situações de trabalho e o assédio como estratégia de gestão, sendo este último tópico também tematizado por Gaulejac ${ }^{23}$. A partir desses pontos e tomando alguns casos concretos como exemplo, como o de trabalhadores de call centers, Antunes busca relacionar como as tecnologias do século XXI se articulam com condições de trabalho do século XX.

Há, então, uma centralidade do debate sobre trabalho digital e a sua concretude, ou seja, sua inseparabilidade em relação aos processos produtivos e à economia de maneira geral, seguindo Huws ${ }^{24}$. Conforme Antunes ${ }^{25}$, "as atividades on-line avançam, inserindo-se crescentemente nas complexas cadeias produtivas globais". Isto é, "as chamadas atividades 'virtuais' são dependentes e têm conexões fortes com o mundo da materialidade" ${ }^{26}$. Essa "recorporificação" ${ }^{27}$ do digital pode se relacionar a outras obras, como as de Jack Qiu sobre os circuitos de trabalho envolvendo a produção do iPhone desde a Foxconn ${ }^{28}$ e acerca da classe trabalhadora "digital" chinesa ${ }^{29}$. Dessa maneira, o autor não compactua com visões hegemônicas que idealizam o mundo do trabalho a partir da "ideologia do Vale do Silício"30.

No âmbito da sociologia do trabalho, Antunes ${ }^{31}$ avança ao tematizar o impacto - sempre dialético - das tecnologias digitais (ou do que chama de "era digital") nas atividades de trabalho e nos processos produtivos. Contudo ele poderia aproveitar melhor o diálogo com a pesquisa em comunicação para fazer avançar seus argumentos. Do modo como está no livro, o digital, embora importante ao longo da explanação, aparece somente como um apêndice no sentido teórico. Isso pode ser verificado em expressões pouco desenvolvidas como "sociedade digitalizada e tecnologizada" - sendo que podemos considerar a tecnologia sempre como fruto do trabalho humano, em todas as épocas, como teoriza Vieira Pinto ${ }^{32}$ - e "capitalismo financeiro da era informacional" - expressão que deixa entrever que a informação é, de alguma maneira, descolada dos processos de produção, relembrando metáforas idealizadas principalmente nos
19. ANTUNES, 2018, p. 59.

20. HABERMAS, Jürgen Teoria do agir comunicativo. São Paulo: Martins Fontes, 2016.v. 2.

21. BOLTANSKI, LUC; CHIAPELLO, Éve. O novo espírito do capitalismo. São Paulo: Martins Fontes, 2009

22. DARDOT; LAVAL, op. cit.

23. GAULEJAC, Vincent de. Gestão como doença social: ideologia, poder gerencialista e fragmentação social. Aparecida, SP: Ideias e Letras, 2007.

24. HUWS, Ursula. Mundo material: o mito da economia imaterial. Mediações, Londrina, v. 16, n. 1, p. 24 54, 2011.

25. ANTUNES, 2018, p. 48.

26. Ibidem, p. 50

27. HUWS, 2011.

28. QIU, Jack; GREGG, Melisa; CRAWFORD, Kate. Circuits of labour: a labour theory of the iPhone era. TripleC, London, v. 12, n. 2 , p. 564-581, 2014.

29. QIU, Jack. China's digital working class and circuits of labor. Communication and the Public, Hangzhou, v. 3, n. 1, p. 5-18, 2018

30. SCHRADIE, Jen. Ideologia do Vale do Silício e desigualdades de classe: um imposto virtual em relação à política digital. Parágrafo, São Paulo, v. 5, n. 1, p. 85 99, 2017.

31. ANTUNES, 2018, p. 50.

32. VIEIRA PINTO, Álvaro. $\mathrm{O}$ conceito de tecnologia Rio de Janeiro: Contraponto, 2005. 
33. AMPUJA, Marko. A sociedade em rede, o cosmopolitismo e o "sublime digital": reflexões sobre como a história tem sido esquecida na teoria social contemporânea. Parágrafo, São Paulo, v. 3, n. 1, p. 55 67, 2015.

34. QIU, Jack. Goodbye islave: a manifesto for digital abolition. Urbana: University of Illinois Press, 2016.

35. SCHOLZ, Trebor. Uberworked and underpaid London: Polity Press, 2016.

36. SLEE, Tom. Uberização: a nova onda do trabalho precarizado. São Paulo: Elefante, 2017.

37. ROSENBLAT, Alex. Uberland: how algorithms are rewriting the rules of work. Berkeley: University of California Press, 2018.

38. ANTUNES, 2018, p. 35.

39. SRNICEK, Nick. Platform Capitalism. London: Polity, 2017.

40. Ibidem.

41. Como tratado, por exemplo, em outro contexto, por: ABILIO, Ludmila Costhek. Sem maquiagem. São Paulo: Boitempo, 2014.

42. SCHOLZ, op. cit.

43. ROSENBLAT, op. cit.

44. SRNICEK, op. cit., p. 43.

45. VAN DIJCK, José; POELL, Thomas; DEWAAL, Martijn. The platform society: public values in a connective world. New York: Oxford, 2018

46. ANTUNES, 2018.

47. Salvo exceções, como: ZEHLE, Soenke; ROSSITER Ned. Mediations of labor: algorithmic architectures, logistical media, and the rise of Black Box Politics. In: MAXWELL, Richard (org.).

The Routledge Companion to Labor and Media.

New York: Routledge, 2017. p. 40-50.

48. ANTUNES, 2018, p. 37. 49. SRNICEK, op. cit. anos 1990 a partir de uma compreensão não histórica das tecnologias da comunicação, como pontua Ampuja ${ }^{33}$.

Certamente, não é essa a visão de Antunes - até porque o autor trata das novas formas de expropriação de valor em relação ao trabalho digital -, mas essas expressões, colocadas de maneira naturalizada, são indícios da falta de um maior diálogo com outras pesquisas da área. Isso acontece igualmente com as expressões "escravidão digital”, também tematizada por Qiu ${ }^{34}$, e "uberização", analisada por Scholz ${ }^{35}$, Slee ${ }^{36}$ e Rosenblat ${ }^{37}$. No caso da Uber, Antunes a descreve como uma "empresa privada global de assalariamento disfarçado sob a forma de trabalho desregulamentado" que se apropria "do mais-valor gerado pelos serviços dos motoristas" 38 sob a fachada de um aplicativo, em acordo com o que diz Srnicek ${ }^{39}$ acerca do "capitalismo de plataforma".

Consideremos a colocação de Antunes como um ponto de partida para pensarmos: o que é exatamente novo nessa chamada "uberização" em relação a processos produtivos e comunicacionais envolvendo, inclusive, extração de valor? Como essas questões variam a depender do tipo de plataforma envolvida - nos termos de Srnicek ${ }^{40}$, publicitárias, industriais, de produto, em nuvem (cloud), e lean, sendo este último exemplificado pelo próprio Uber e pelo Airbnb? Como são as dinâmicas de trabalho-consumo ${ }^{41}$ envolvidas nessas plataformas e como são as condições e as contradições do trabalho "uberizado" - como, de alguma maneira, tratam Scholz ${ }^{42}$ e Rosenblat ${ }^{43}$ ? Como avançar nas inter-relações entre plataforma - conceituada por Srnicek como "infraestruturas digitais que possibilitam a interação entre dois ou mais grupos" ${ }^{4}$, e também abordada por van Dijck, Poell e de Waal $^{45}$ - e as materialidades do trabalho digital a partir do ponto de vista de sujeitos que trabalham?

Contudo, mesmo que isso não se efetive enquanto um maior diálogo com pesquisas sobre trabalho e tecnologias digitais, já há em Antunes ${ }^{46}$ uma contribuição à própria pesquisa em comunicação, pois trata da "internet das coisas" - algo fetichizado e idealizado no campo da comunicação ${ }^{47}$ - de forma crítica e a partir do ponto de vista do trabalho. Isto é, para Antunes, a internet das coisas simboliza o controle "informacional-digital" da produção, tendo por consequência "a ampliação do trabalho morto, tendo o maquinário digital - a 'internet das coisas' - como dominante e condutor de todo o processo fabril"

Isso poderia ser desenvolvido a partir da consideração de que a extração de dados possui funções-chave no capitalismo e na comunicação contemporaneamente, conforme Srnicek ${ }^{49}$ e Turow e Couldry ${ }^{50}$, enfatizando o papel da comunicação na "dataficação" da produção. Segundo Srnicek, os dados podem "formar e dar vantagens competitivas aos algoritmos, permitir a terceirização de trabalhadores e a otimização e a flexibilidade dos processos produtivos" ${ }^{52}$. Ainda, os dados podem servir para controle e vigilância dos trabalhadores, e os dados pessoais de usuários podem servir como capital fixo e circulante, conforme Fuchs ${ }^{53}$.

A partir do contexto acima, principalmente em relação à internet das coisas, podemos depreender que, se a comunicação ainda é um ponto-cego para 
as pesquisas em sociologia do trabalho, os pontos de vista da produção e do mundo do trabalho ainda são um ponto-cego para a pesquisa em comunicação, principalmente para as que tem como objeto central as mídias digitais, tratando-as como se fossem descoladas dos processos produtivos e das cadeias de valor. No sentido ainda de apontar "a falta que a comunicação faz" na obra de Antunes, ressaltamos três pontos.

O primeiro é o sensível capítulo sobre as fotografias do trabalho precário global, em que são descritos filmes sobre o atual cenário do mundo do trabalho, que poderia render uma análise mais aprofundada, em perspectiva comunicacional, para além da mera descrição. Em seguida, destacamos a descrição sobre "frilas fixos", na acepção do autor: "freelancers que se tornam permanentes, mas que têm seus direitos burlados e se escondem nas redações de jornais quando as empresas sofrem as auditorias de trabalho" ${ }^{24}$. Há, na própria exemplificação de Antunes, uma relação com o mundo do trabalho da comunicação, em especial dos jornalistas, mas não há diálogo com pesquisas que têm trabalhado sobre esse tema na comunicação $0^{55}$, ao mostrarem as contradições de se trabalhar como freelancer, inclusive como "frila fixo", em um mundo do trabalho marcado pelas tecnologias digitais e pela flexibilização do trabalho.

Um terceiro ponto é a constatação, por parte de Antunes, de um "novo dicionário corporativo", com termos como "resiliência", "colaboradores" e "metas" - como um contraponto à gestão destrutiva em relação ao mundo do trabalho. Pois a gramática corporativa vinha sofrendo modificações desde o fim dos anos 1990, como mostra Fígaro ${ }^{57}$ em relação à apropriação dos sentidos pelo discurso empresarial. Essa dimensão da comunicação/linguagem sobre o trabalho ${ }^{58}$ tem sido uma preocupação de estudos sobre o mundo do trabalho na comunicação, inclusive tomando a linguagem como mercado, no sentido dado por RossiLandi ${ }^{59}$ de observar "quais são as regularidades que regem a circulação das palavras, expressões e mensagens, começando pelos valores segundo os quais elas são consumidas e trocadas" ${ }^{\prime 0}$. Isso significa que há valor nos signos circulantes, compondo uma gramática que, por um lado, convoca ${ }^{61}$ os sujeitos a agirem de determinados modos (flexibilidade, inovação, disrupção, resiliência, empreendedorismo) em detrimento de outros, de modo a prescrever sujeitos de sucesso; e, por outro, justifica ${ }^{62}$ os modos de ser/existir no capitalismo, como atenuadores do "privilégio da servidão" ${ }^{63}$. Assim, o ponto-cego comunicacional na obra de Antunes ${ }^{64}$ impede que se entreveja a comunicação como articuladora e braço-auxiliar do modo de produção capitalista ${ }^{65}$, inclusive da financeira, por meio da circulação do capital.

A circulação do capital é tematizada em $O$ privilégio da servidão, inclusive abordando o papel dos meios de transporte em relação à circulação de mercadorias. Nesse sentido, Antunes ${ }^{66}$ aponta corretamente, a partir de uma visão marxiana, que há um processo de produção envolvido no processo de circulação. Teoriza, assim, questões de tempo de produção, tempo de circulação e processo de produção de mais-valor, considerando que a indústria de transportes se torna “imprescindível para a concretização da produção material e da efetivação do
50. TUROW, Joseph; COULDRY, Nick. Media as data extraction: towards a new map of a transformed communication field. Journal of Communication, Oxford, v. 68, n. 2, p. 415-423, 2017.

51. BREITER, Andreas; HEPP, Andreas. The complexity of datafication: putting digital traces in context. In: HEPP, Andreas; BREITER, Andreas; HASEBRINK, Uwe (org.). Communicative figurations: transforming communications. London: Palgrave, 2018. p. 387-405.

52. SRNICEK, op. cit., p. 41-42.

53. FUCHS, Christian. Social media: a critical introduction. London: Sage, 2017.

54. ANTUNES, 2018, p. 36-37.

55. Cf. GROHMANN, Rafael. Os discursos dos jornalistas freelancers sobre o trabalho: comunicação, mediações e recepção. Dissertação (Mestrado em Ciências da Comunicação) - Escola de Comunicação e Artes, Universidade de São Paulo São Paulo, 2012; e FÍGARO, Roseli; NONATO, Cláudia; GROHMANN, Rafael. As mudanças no mundo do trabalho do jornalista. São Paulo: Atlas, 2013.

56. ANTUNES, 2018, p. 38.

57. FÍGARO, Roseli. Relações de comunicação no mundo do trabalho. São Paulo: Annablume, 2008.

58. NOUROUDINE, Abdallah. A linguagem: dispositivo revelador da complexidade do trabalho. In: SOUZA-E-SILVA, Maria Cecília; FAIITA, Daniel. Linguagem e trabalho: construção de objetos de análise no Brasil e na França. São Paulo: Cortez, 2002. p. 17-30.

59. ROSSI-LANDI, Ferrucio. A linguagem como trabaIho e como mercado: uma teoria da produção e da alienação linguística. São Paulo: Difel, 1985.

60. Ibidem, p. 85.

61. PRADO, José Luiz Aidar. Convocações biopolíticas dos dispositivos comunicacionais. São Paulo: Educ, 2013. 
62. BOLTANSKI; CHIAPELLO, op. cit.

63. ANTUNES, 2018.

64. Ibidem

65. SODRÉ, Muniz. A ciência do comum. Petrópolis: Vozes, 2014.

66. ANTUNES, 2018.

67. Ibidem, p. 43.

68. MARX, Karl. Grundrisse. São Paulo: Boitempo, 2011.

69. ANTUNES, 2018.

70. WILLIAMS, Raymond. Meios de comunicação como meios de produção. In:___ Cultura e materialismo. São Paulo: Unesp, 2011. p. 69-85.

71. ANTUNES, 2018, p. 172.

72. Ibidem, p. 257.

73. Também trabalhado em sua atualidade em: DU RAND, Cedric. El capital ficticio. Barcelona: NED 2018.

74. MARX, Karl. O capital. São Paulo: Boitempo, 2017. v. 3 .

75. SODRÉ, op. cit.

76. HUWS, 2014.

77. ANTUNES, 2018, p. 80.

78. NEGRI, Antonio; HARDT, Michael. Multidão. Rio de Janeiro: Record, 2005.

79. GORZ, André. O imaterial. São Paulo: Annablume, 2005.

80. HUWS, 2011, p. 52.

81. ANTUNES, 2018, p. 83.

82. HUWS, 2011, p. 28. mais-valor" ${ }^{67}$. Contudo, o próprio Marx ${ }^{68}$, nos Grundrisse, ressalta o papel central não só dos meios de transporte, mas também dos meios de comunicação - algo esquecido por Antunes ${ }^{69}$ - em relação à circulação do capital. Isto é, a comunicação, tanto como meio de produção ${ }^{70}$ quanto de circulação, atua no modo de produção capitalista em relação à extração de mais-valia, inclusive na própria "dataficação da produção", anteriormente mencionada.

Junto à circulação do capital, outro tema tratado por Antunes é o da financeirização, considerando o "capital financeiro no cume e [o] trabalho desregulado nas cadeias produtivas de valor" ${ }^{71}$. Um ponto importante é o não deslocamento do capital financeiro em relação ao capital produtivo, sendo que o próprio "capital financeiro atua na esfera produtiva (e a controla)"72. Nesse sentido, apenas o chamado "capital fictício"73 - já presente no terceiro volume de $O$ capital $^{74}$ - se descolaria da produção. No entanto, novamente, há uma invisibilidade em relação ao papel da comunicação - sem nenhum prejuízo ao autor, já que essa questão não está na agenda de suas pesquisas - no processo de financeirização, ao que Sodré ${ }^{75}$ chama de "financeirização da comunicação".

Como podemos ver, as novas (e velhas) formas de extração de mais-valor no capitalismo contemporâneo, incluindo o trabalho digital, fazem parte do escopo da obra de Antunes, com eco nas pesquisas de $\mathrm{Huws}^{76}$, por exemplo, evidenciando a pertinência da lei do valor marxiana na atualidade. Nesse contexto insere-se também o debate sobre trabalho material e imaterial, em que o autor se pergunta: "essas atividades tidas como predominantemente imateriais têm ou não conexões com os complexos mecanismos da lei do valor hoje operantes em seu processo de valorização?"77. Antunes, então, observa novos mecanismos de extração de sobretrabalho nas atividades tidas como "imateriais" e se contrapõe frontalmente a teses, como as de Negri e Hardt ${ }^{78}$ ou de Gorz ${ }^{79}$, sobre o "trabalho imaterial", que extirpam tanto o valor quanto a "materialidade redundante, bagunçada, vulnerável" ${ }^{00}$ dos seres humanos, principalmente no contexto do Sul global. De acordo com Antunes ${ }^{81}$, André Gorz,

ao converter o trabalho imaterial como dominante e mesmo determinante no capitalismo atual e desvinculado da geração de valor, acabou por realizar um bloqueio que comprometeu a possibilidade de compreender as novas modalidades e formas de vigência dessa lei, modalidades essas que se encontram presentes no novo proletariado de serviços (o cibertariado ou infoproletariado), que exerce atividades de perfil acentuadamente imaterial, mas que são parte constitutiva da criação de valor e mais ou menos imbricada com os trabalhos materiais. [...] Não é demais lembrar que as formulações que hiperdimensionam o trabalho imaterial e o convertem em elemento dominante frequentemente desconsideram as tendências empíricas presentes no mundo do trabalho no Sul global.

Em nossa visão, o fato de o produto de um trabalho ser considerado intangível ou digital não significa dizer que os processos produtivos são "imateriais", pois, como afirma Huws ${ }^{82}$, "os produtos culturais, tais como livros, filmes, 'ciência' ou propaganda - e as 'ideias' que eles contêm (no mínimo, 
considerando que são resultado consciente de esforço mental), são também produtos de trabalho humano, intelectual e físico". Ou, conforme Tosel ${ }^{83}$, "o imaterial é uma forma de materialidade como o é o simbólico", resultando, pois, em produtos de quaisquer ordens que dependem do trabalho - que é sempre mental e corporal - de homens e mulheres na cadeia produtiva de valor. Nesse mesmo sentido, Marcos Dantas ${ }^{84}$ refuta completamente a categoria de "trabalho imaterial", ao afirmar que

o trabalho informacional é material, pois é transformação, pelo corpo humano e sua mente, através de próteses adequadas (ferramentas e tecnologias), de materiais portadores de signos que contém valor pelo signo que portam. Trabalho imaterial somente se for aquele feito por Deus no ato da criação... ${ }^{85}$

Essa percepção é compartilhada por $\mathrm{Huws}^{86}$ e $\mathrm{Scholz}^{87}$ em relação ao trabalho digital. Para Huws, a internet depende de geração de energia, disjuntores, lançamento de satélites, "edifícios onde as mercadorias são projetadas, montadas e vendidas" 88 , entre outros produtos materiais. Nesse sentido, Scholz ${ }^{89}$ afirma que "o trabalho digital pode ser tudo menos imaterial; é um setor da economia, um conjunto de atividades humanas baseado nas cadeias globais de trabalho material", tratando-se, portanto, de atividades humanas realizadas por meio de diversos dispositivos e plataformas.

Essa não é exatamente a mesma visão de Antunes ${ }^{90}$, pois o autor coloca que o próprio Marx, em capítulo inédito de $O$ capital $^{91}$, já abordava a existência de "produção não material", não se tratando, pois, de algo inexistente. Contudo, para ele, a categoria não possui a dimensão propalada por Gorz ${ }^{92}$ e por Negri e Hardt $^{93}$ em relação à extração de valor e produção/circulação do capital. Nesse contexto, para Antunes ${ }^{94}$, expressões como "sociedade baseada no conhecimento e trabalho imaterial são, antes de tudo, expressões da complexificação atingida pela divisão do trabalho, em que coexistem tanto as atividades intelectuais como as manuais, tanto as de criação como aquelas mais rotineiras". Podemos questionar as separações entre trabalho material-imaterial, manual-intelectual (como mostra Sohn-Rethel ${ }^{95}$ ) e criativo-rotineiro? Em que medida essas expressões, do modo como estão colocadas, nos ajudam a compreender a "dança dialética" ${ }^{96}$ do mundo do trabalho contemporâneo sem cair em reducionismos ou adjetivações? Como questiona Huws ${ }^{97}$, "por que o desejo de classificar esses trabalhadores? E por que particularmente agora"?

$\mathrm{Na}$ contramão dessas classificações, outra contribuição de Antunes, desde Os sentidos do trabalho ${ }^{98}$, é a categoria de "classe-que-vive-do-trabalho", ou seja, uma visão ampliada de classe trabalhadora que considera sua composição heterogênea e as reconfigurações e novas morfologias de classe. Estariam excluídos da classe trabalhadora, na visão do autor, gestores do capital, pequenos empresários e a pequena burguesia urbana e rural, além dos que vivem de juros e especulação. Essa visão acerca da "classe-que-vive-do-trabalho" reafirma, pois, a centralidade da luta de classes e das classes sociais para a sociedade contemporânea ${ }^{99}$, levando em conta as mutações nas formações de classes.
83. TOSEL, André. Teoria política e trabalho imaterial em Marx. Entrevista cedida a Henrique Amorim. Lutas Sociais, São Paulo, n. 23, 2009, p. 167.

84. DANTAS, Marcos. Trabalho com informação: valor, acumulação, apropriação nas redes do capital. Rio de Janeiro: CFCH, 2012.

85. Ibidem, p. 17-18.

86. HUWS, 2014.

87. SCHOLZ, op. cit.

88. HUWS, 2014, p. 157.

89. SCHOLZ, op. cit., p. 6 .

90. ANTUNES, 2018.

91. MARX, Karl. O capital livro I: capítulo VI (inédito). 1. ed. São Paulo: Livraria Editora Ciências Humanas, 1978

92. GORZ, op. cit.

93. NEGRI; HARDT, op. cit. 94. ANTUNES, 2018, p. 43.

95. SOHN-RETHEL, Alfred. Intellectual and manual labor: a critique of epistemology. New Jersey: Humanities Press, 1978.

96. HUWS, 2014.

97. HUWS, Ursula. Aignição no motor: trabalhadores criativos na economia global. Parágrafo, São Paulo, v. 3, n. 1, p. 85-92, 2015.

\section{ANTUNES, 2001.}

99. Como procuramos mostrar em relação à comunicação em: GROHMANN, Rafael. As classes sociais na comunicação: sentidos teóricos do conceito. Tese (Doutorado em Ciências da Comunicação) - Escola de Comunicação e Artes, Universidade de São Paulo, São Paulo, 2016. 
100. ANTUNES, 2018, p. 87.

101. Ibidem, p. 87.

102. Ibidem, p. 303.

103. Ibidem, p. 303.

104. BOURDIEU, Pierre. A distinção: crítica social do julgamento. São Paulo: Edusp, 2007.

105. ANTUNES, 2018, p. 54

106. A exemplo de: BURAWOY, Michael. O marxismo encontra Bourdieu. Campinas: Editora Unicamp, 2010; ou mesmo o que propomos em: GROHMANN 2016.

107. RONSINI, Veneza. A crença no mérito e a desigualdade. São Paulo: Sulina, 2012.

108. ANTUNES, 2018, p. 54

109. Ibidem, p. 244-citação esta destinada aos partidos de esquerda.

110. LUKÁCS, Gyorgy. Para uma ontologia do ser social I. São Paulo: Boitempo, 2012. p. 293.
O autor considera curioso discursos sobre descentramento de categorias de classes e trabalho aparecerem justamente em um momento em que "se amplia enormemente o conjunto de seres sociais que vivem da venda de sua força de trabalho, em escala planetária"100. Para Antunes, "o centro da transformação social ainda está radicado no conjunto da classe trabalhadora"101 e, por isso, é essencial evitar determinadas fraturas ou divisões de classe. Isso significa compreender sua complexidade e heterogeneidade, por exemplo: (1) relações com questões raciais, étnicas, geracionais e de gênero, e que têm "cada vez mais uma conformação mundializada"102; (2) conexões "entre trabalhadores 'estáveis' e precarizados, entre nacionais e imigrantes"103, consideradas fraturas impostas pelo capital à classe trabalhadora; (3) a problemática das definições de classes médias.

Em relação a este último ponto, Antunes chega a citar Bourdieu ${ }^{104}$ - algo raro em seu percurso -, mesmo de forma breve, para afirmar que "as classes médias, além de suas diferenciações e oscilações estruturais típicas, definem-se de forma significativa pelos valores culturais, simbólicos, de consumo"105. Essa constatação nos leva a refletir que seria interessante um refinamento (ou uma maior problematização) na relação entre marxismo e Bourdieu ${ }^{106}$. Outro ponto em relação às classes médias que renderia pesquisas empíricas mais focadas por exemplo, como são, na área de comunicação, as pesquisas de Ronsini ${ }^{107}$, em uma perspectiva bourdiana - é a questão colocada por Antunes ${ }^{108}$ de que a "consciência das classes médias aparece frequentemente como consciência de uma não classe".

Enfim, os retratos conceituais e empíricos trazidos por Antunes revelam uma preocupação de compreender condições, contradições e complexidades do mundo do trabalho atualmente, conectando conceitos discutidos principalmente na Europa e na América do Norte a uma perspectiva nacional e do Sul global, com um olhar, ao mesmo tempo, que constata o "privilégio da servidão" no estágio atual de devastação do mundo do trabalho, mas com uma perspectiva - como "luz no fim do túnel" - de uma vida cheia de sentido, tanto dentro quanto fora do mundo do trabalho. Quanto ao nosso papel como pesquisadores, isso passa tanto por entender seu diagnóstico em relação ao mundo do trabalho quanto por nos reconectarmos efetivamente à "vida cotidiana, do dia a dia dos homens e mulheres que vivem de seu trabalho"109, sem ficarmos ensimesmados em nossos espaços institucionais e nos pequenos poderes "de campo". A vida concreta de sujeitos sociais, como afirma Lukács: "a ciência brota da vida, e na vida mesmo"110.

\section{REFERÊNCIAS BIBLIOGRÁFICAS}

ABILIO, Ludmila Costhek. Sem maquiagem. São Paulo: Boitempo, 2014.

AMPUJA, Marko. A sociedade em rede, o cosmopolitismo e o "sublime digital": reflexões sobre como a história tem sido esquecida na teoria social contemporânea. Parágrafo, São Paulo, v. 3, n. 1, p. 55-67, 2015. 
ANTUNES, Ricardo. Os sentidos do trabalho. São Paulo: Boitempo, 2001.

- O privilégio da servidão: o novo proletariado de serviços na era digital. São Paulo: Boitempo, 2018.

BOLTANSKI, Luc; CHIAPELLO, Éve. O novo espírito do capitalismo. São Paulo: Martins Fontes, 2009.

BOURDIEU, Pierre. A distinção: crítica social do julgamento. São Paulo: Edusp, 2007.

BREITER, Andreas; HEPP, Andreas. The complexity of datafication: putting digital traces in context. In: HEPP, Andreas; BREITER, Andreas; HASEBRINK, Uwe (org.). Communicative figurations: transforming communications. London: Palgrave, 2018. p. 387-405.

BROWN, Wendy. El pueblo sin atributos: la secreta revolución del neoliberalismo. Barcelona: Malpaso, 2016.

BURAWOY, Michael. O marxismo encontra Bourdieu. Campinas: Editora Unicamp, 2010.

CARVALHO, Laura. Valsa brasileira: do boom ao caos econômico. São Paulo: Todavia, 2018.

DANTAS, Marcos. Trabalho com informação: valor, acumulação, apropriação nas redes do capital. Rio de Janeiro: CFCH, 2012.

DARDOT, Pierre; LAVAL, Christian. A nova razão do mundo. São Paulo: Boitempo, 2016.

DURAND, Cedric. El capital ficticio. Barcelona: NED, 2018.

FERNANDES, Florestan. A Revolução Burguesa no Brasil. São Paulo: Globo, 2006.

FÍGARO, Roseli. Relações de comunicação no mundo do trabalho. São Paulo: Annablume, 2008.

FÍGARO, Roseli; NONATO, Cláudia; GROHMANN, Rafael. As mudanças no mundo do trabalho do jornalista. São Paulo: Atlas, 2013.

FISHER, Mark. Capitalist Realism: is there no alternative? Winchester: Zero Books, 2011.

FUCHS, Christian. Social media: a critical introduction. London: Sage, 2017.

GAULEJAC, Vincent de. Gestão como doença social: ideologia, poder gerencialista e fragmentação social. Aparecida, SP: Ideias e Letras, 2007.

GORZ, André. O imaterial. São Paulo: Annablume, 2005.

GROHMANN, Rafael. Os discursos dos jornalistas freelancers sobre o trabalho: comunicação, mediações e recepção. Dissertação (Mestrado em 
Ciências da Comunicação) - Escola de Comunicação e Artes, Universidade de São Paulo, São Paulo, 2012.

As classes sociais na comunicação: sentidos teóricos do conceito. Tese (Doutorado em Ciências da Comunicação) - Escola de Comunicação e Artes, Universidade de São Paulo, São Paulo, 2016.

HABERMAS, Jürgen. Teoria do agir comunicativo. São Paulo: Martins Fontes, 2016. v. 2.

HUWS, Ursula. Mundo material: o mito da economia imaterial. Mediações, Londrina, v. 16, n. 1, p. 24-54, 2011.

2014 .

Labor in the global digital economy. New York: Monthly Review Press,

A ignição no motor: trabalhadores criativos na economia global. Parágrafo, São Paulo, v. 3, n. 1, p. 85-92, 2015.

LUKÁCS, Gyorgy. Para uma ontologia do ser social I. São Paulo: Boitempo, 2012.

MARX, Karl. O capital: livro I: capítulo VI (inédito). 1. ed. São Paulo: Livraria Editora Ciências Humanas, 1978.

. Grundrisse. São Paulo: Boitempo, 2011.

. O capital. São Paulo: Boitempo, 2017. v. 3.

MURDOCK, Graham. Refeudalização revisitada: a destruição da democracia deliberativa. MATRIZes, São Paulo, v. 12, n. 2, p. 13-31, 2018.

NEGRI, Antonio; HARDT, Michael. Multidão. Rio de Janeiro: Record, 2005.

NOUROUDINE, Abdallah. A linguagem: dispositivo revelador da complexidade do trabalho. In: SOUZA-E-SILVA, Maria Cecília; FAÏTA, Daniel. Linguagem e trabalho: construção de objetos de análise no Brasil e na França. São Paulo: Cortez, 2002. p. 17-30.

PRADO, José Luiz Aidar. Convocações biopolíticas dos dispositivos comunicacionais. São Paulo: Educ, 2013.

PRADO JÚNIOR, Caio. Formação do Brasil contemporâneo. São Paulo: Companhia das Letras, 2011.

QIU, Jack. Goodbye iSlave: a manifesto for digital abolition. Urbana: University of Illinois Press, 2016.

. China's digital working class and circuits of labor. Communication and the Public, Hangzhou, v. 3, n. 1, p. 5-18, 2018.

QIU, Jack; GREGG, Melisa; CRAWFORD, Kate. Circuits of Labour: a labour theory of the iPhone era. TripleC, London, v. 12, n. 2, p. 564-581, 2014. 
RONSINI, Veneza. A crença no mérito e a desigualdade. São Paulo: Sulina, 2012.

ROSENBLAT, Alex. Uberland: how algorithms are rewriting the rules of work. Berkeley: University of California Press, 2018.

ROSSI-LANDI, Ferrucio. A linguagem como trabalho e como mercado: uma teoria da produção e da alienação linguística. São Paulo: Difel, 1985.

SCHOLZ, Trebor. Uberworked and underpaid. London: Polity Press, 2016.

SCHRADIE, Jen. Ideologia do Vale do Silício e desigualdades de classe: um imposto virtual em relação à política digital. Parágrafo, São Paulo, v. 5, n. 1, p. 85-99, 2017.

SINGER, André. O lulismo em crise: um quebra-cabeça do período Dilma (2011-2016). São Paulo: Companhia das Letras, 2018.

SLEE, Tom. Uberização: a nova onda do trabalho precarizado. São Paulo: Elefante, 2017.

SODRÉ, Muniz. A ciência do comum. Petrópolis: Vozes, 2014.

SOHN-RETHEL, Alfred. Intellectual and manual labor: a critique of epistemology. New Jersey: Humanities Press, 1978.

SRNICEK, Nick. Platform Capitalism. London: Polity, 2017.

TOSEL, André. Teoria política e trabalho imaterial em Marx. Entrevista cedida a Henrique Amorim. Lutas Sociais, São Paulo, n. 23, p. 163-169, 2009.

TUROW, Joseph; COULDRY, Nick. Media as data extraction: towards a new map of a transformed communication field. Journal of Communication, Oxford, v. 68, n. 2, p. 415-423, 2017.

VAN DIJCK, José; POELL, Thomas; DE WAAL, Martijn. The platform society: public values in a connective world. New York: Oxford, 2018.

VIEIRA PINTO, Álvaro. O conceito de tecnologia. Rio de Janeiro: Contraponto, 2005.

WILLIAMS, Raymond. Meios de comunicação como meios de produção. In: . Cultura e materialismo. Tradução André Glaser. São Paulo: Editora Unesp, 2011. p. 69-85.

ZEHLE, Soenke; ROSSITER, Ned. Mediations of labor: algorithmic architectures, logistical media, and the rise of Black Box Politics. In: MAXWELL, Richard (org.). The Routledge Companion to Labor and Media. New York: Routledge, 2017. p. 40-50. 
